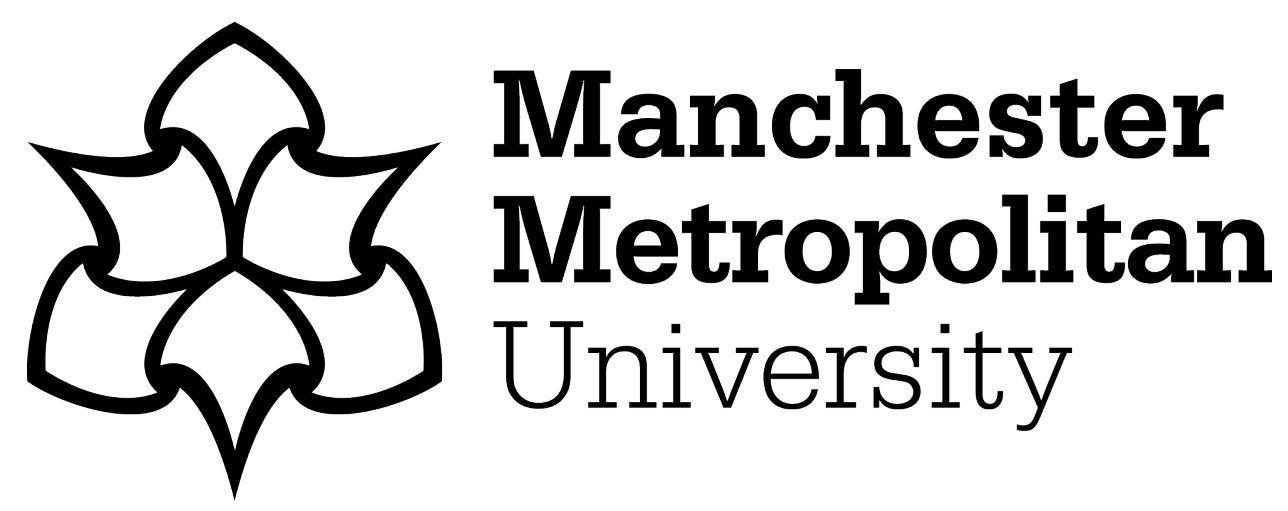

Wilkinson, Catherine and Wilkinson, Samantha ORCID logoORCID: https://orcid.org/0000-0002-1564-5472 (2019) The only way is ethics? Applying for National Health Service ethical approval and governance for research with children. Children's Geographies, 17 (4). pp. 480-486. ISSN 1473-3277

Downloaded from: https://e-space.mmu.ac.uk/622761/

Version: Accepted Version

Publisher: Taylor \& Francis (Routledge)

DOI: https://doi.org/10.1080/14733285.2019.1592112

Please cite the published version 


\title{
The only way is ethics? Applying for National Health Service ethical approval and governance for research with children
}

Dr Catherine Wilkinson and Dr Samantha Wilkinson

\begin{abstract}
In this Viewpoints piece, we reflect on the process of applying for National Health Service (NHS) ethical approval and governance for research with children in England. We present a case study of our experiences of navigating the Integrated Research Application System (IRAS) for one study, The Hair Study. We argue that, for children's geographers, getting to grips with the complex processes of applying for NHS ethical approval and governance is important when considering the move towards interdisciplinary working, and engagement with children in underexplored spaces and places, such as: doctors surgeries; hospitals; dentists; and other services commissioned by the NHS.
\end{abstract}

Key words: Children; ethics; governance; IRAS; NHS

\section{Introduction}

Obtaining the necessary approvals and permissions for research using the NHS as a setting requires successful navigation of the ethical and Research and Development (R\&D) aspects of the NHS. Difficulties in undertaking research in the NHS in the United Kingdom, due to bureaucratic and inefficient governance processes, have led to the development of the Integrated Research Application System (IRAS) from 2009 (Thompson and France, 2010). IRAS is an online application form, which captures information required by bodies including National Research Ethics Service, NHS Research Ethics Committees (RECs) and NHS R\&D. However, there are arguments that this new system fails to be consistent and streamlined (Thompson and France, 2010), and is "dogged by delay and arbitrary decisions" (Fudge et al. 
2010, p. 635). The complexity of the process has led some scholars (e.g. Rees, 2011; Smajdor et al. 2009) to produce simple guidelines for gaining and expediting ethical approval for novice researchers or medical professionals hoping to engage in research. Notably, there is also an IRAS e-learning module, titled: 'Getting the Best from IRAS' (www.myresearchproject.org.uk/Elearning/module.html), which provides information and tips to make the process easier. This paper aims to enable fellow children's geographers to understand procedures for gaining ethical approval for research with children in NHS settings in England. For children's geographers, getting to grips with the complex processes of applying for NHS ethical approval is important when considering the move towards interdisciplinary working, and engagement with children in spaces and places such as doctors surgeries; hospitals; dentists, and other services commissioned by the NHS that have not been widely researched by children's geographers.

To be clear, NHS ethical permissions must be gained in order to conduct any study that:

- Recruits people who use NHS services, for example patients or carers

- Recruits people employed by the NHS, for example nurses, doctors and other healthcare professionals

- Is conducted on NHS premises

Before a research study can commence, it must be approved by a REC, and by the R\&D Department(s) of NHS Trust(s) where the research is to occur. Such permissions are required to ensure that the rights, safety and wellbeing of research participants are maintained, and to promote high ethical standards (Hadjiconstantinou and Forbat, 2012). Other systems for ethical procedures in medical research operate in other countries, yet our experience is only with NHS ethics in the UK, which is known for its rigour. It should also be noted that different structures 
and governance frameworks exist in England, Scotland, Wales and Northern Ireland, and herein we speak of our experiences of applying through the England strand only.

In this paper we present a case study of our experiences of undergoing ethical approval for The Hair Study ${ }^{I}$, of which we are co-principal investigators, to elucidate the process. This short Viewpoints piece is structured as follows. First, we contextualise the discussion by providing a brief overview of geographical literature on children and ethics. We then detail the process of gaining ethical approval via the NHS. After this, we provide an overview of The Hair Study and the ethical approvals sought for this project. We conclude by situating both the challenges and opportunities of the process of applying for NHS ethical approval within geographical literature on children and ethics.

\section{Children and ethics}

Ensuring research is ethically sound has long been a concern of researchers working directly with children. Notably, there has been a recent surge of formal and institutional ethics requirements, particularly for research with children (Abebe and Bessell, 2014). Of particular concern have been processes of seeking informed consent; remuneration; confidentiality and anonymity. As Ergler et al. (2016) point out, children's geographers have traditionally been at the forefront of problematising ethical procedures, both within and beyond institutions. Many of the geographical debates surrounding ethics in research with children have taken place on the pages of the journal Children's Geographies itself; for instance, elucidating the tensions between ethics, competence and participation (Skelton, 2008); rights, reason and responsibilities (Bell, 2008); critical reflections on ethical guidelines (Abebe and Bessell,

\footnotetext{
${ }^{1}$ The Hair Study comprises an interdisciplinary team: Professor of Children's Nursing Bernie Carter, Consultant Plastic, Reconstructive and Aesthetic Surgeon Professor Partha Vaiude, Clinical Lead of the Burns Service at Alder Hey Children's Hospital Ms Sian Falder, and Hair Restoration Surgeon Dr Bessam Farjo.
} 
2014); and most recently ethics committees (Robson, 2018). Following Abebe and Bessell (2014), research with children should be respectful of children's rights and views, as well as robust and rigorous. The drive for guidelines and processes to promote ethical research with children has resulted in a multi-layered bureaucratic process, running the risk of creating a formulaic, 'tick-a-box' mentality, rather than promoting a set of supported professional values and behaviours (Abebe and Bessell, 2014).

There has for some time been recognition of the value of extending the degree of involvement of children in research in the social sciences, though there is some way to go yet on this journey in medical research (Scally, 2014). Scally (2014) continues that the lack of clear legislative framework for the participation of children in medical and health research, and the removal of the reference to 'minors' in the Declaration of Helsinki ${ }^{2}$, may have adversely affected the confidence of researchers in engaging with this population group.

\section{Gaining ethical approval when using the NHS as a research setting}

There have been arguments that the process of gaining NHS ethical approval prior to IRAS, which involved applying for various permissions in a disparate fashion, threatened the possibility of undertaking health and medical research in the UK (Hallowell et al. 2008). Even with the new more streamlined process, some scholars have demanded a clear national strategy to overcome local barriers to research with the NHS (see Rees and Wells, 2010; Thompson and France, 2010). Others argue that, whilst the current IRAS process is "painstaking” (Rees, 2011, p. 125), and requires a need for perseverance (Amin, 2010), it exists for sound reasons, namely

\footnotetext{
${ }^{2}$ A set of ethical principles regarding human experimentation developed for the medical community by the World Medical Association.
} 
due to highly unethical research undertaken historically which caused unnecessary harm to people (Jonker, Cox and Marshall, 2011). One example of said unethical research is a clinical trial which took place in London in 2006 to test a drug known as TGN1412. The drug had been successfully tested on monkeys and it was hoped that it would eventually revolutionise cancer treatment. The trial left participants fighting for their lives and became known as the 'Elephant Man trial' in the media because of its shocking physical side-effects on the participants (including severely swollen faces). One participant remained in hospital for four months fighting the symptoms of pneumonia, septicaemia and dry gangrene which meant his fingertips fell off and part of his foot and toes had to be amputated. Alarmingly, a BBC documentary reports that the NHS was completely unaware of the trial (see BBC, 2017). Considering the disturbing consequences of research that 'goes wrong', NHS ethics and governance can be considered "a necessary evil" (Hallowell et al. 2008, p. 87).

Indeed, arguably such concerns are not limited to research with the NHS - and whilst ethical guidelines can be thought of as limiting, we join Halse and Honey (2005) in considering them as facilitating good research practice during data collection, analysis, and even dissemination. However, it must be noted that, whilst principles for ethical research and ethics committees have a role to play in promoting ethical research, in practice guidelines can become inflexible rules that must be adhered to (Abebe and Bessell, 2014).

\section{Approval for The Hair Study}

The Hair Study will be the first research project in the world to explore a cohort of children within a single tertiary paediatric setting, Alder Hey Children's Hospital, Liverpool, UK, who are undergoing hair reconstruction. The research question this project will address is: 'what are the physical and psychosocial impacts of alopecia and hair transplant surgery on children and young people with alopecia both whilst waiting for surgery, and in the 12-24 months post first 
transplant?' This study will use an exploratory, participatory, longitudinal, mixed methods design (Creswell et al., 2011) to generate qualitative (observation, interviews, diaries, activities) and descriptive quantitative (global scales, key clinical/demographic information) data with children and young people aged 7-18 years ${ }^{3}$. The Hair Study is a longitudinal study which will enable us to track the children/young people at the four key time points that align with routine scheduled clinic visits:

- Pre-transplant visit ( 2 weeks-4 months prior to transplant): focusing on perceptions of alopecia and hopes and expectations of hair transplant;

- 6 months post-transplant: focusing on their experience post-transplant, including perception of success of transplant, any changes in sense of self;

- 12 months post-transplant: this would coincide with assessment for whether they will need a second transplant; and

\section{- 24 months post-first transplant}

Ethical approval was gained from the Faculty of Health and Social Care at Edge Hill University on $28^{\text {th }}$ March 2018. After Faculty ethical approval was gained, we registered the study on the IRAS website on $9^{\text {th }}$ May 2018 and began to apply for the permissions. The main timeconsuming activity is writing the extensive online application form via IRAS. Although the IRAS system has been designed to minimise the amount of duplication and requests for information (Thompson and France, 2010), the main section of our ${ }^{4}$ IRAS form had 78 questions. These questions ranged from things like "is your project research ${ }^{5}$ ?" through to

\footnotetext{
${ }^{3}$ This age range was initially proposed as 4-18 years, we provide a discussion of why this was adjusted below in this paper.

${ }^{4}$ We say 'our' as everyone's IRAS form will differ in length, as the form removes or adds questions dependent on answers provided to Project Filter questions etc.

${ }^{5}$ NRES provides useful guidance to inform researchers how to distinguish between research, audit and service evaluation.
} 
"what are the potential risks and burdens for research participants and how will you minimise them?" Amin (2010), writing about her experiences as a fourth-year student completing the new IRAS application process, documents that she found many sections containing confusing fields, including sponsorship and insurance. Our experience echoed that of Amin (2010). Completing these sections requires liaison with the Research Office, or equivalent, within your institution who can provide administrative oversight.

When we indicated on the IRAS form that we would be researching with children, the form generated, to our surprise, only a further four additional questions specific to this population group:

1. Please specify the potential age range of children under 16 who will be included and give reasons for carrying out the research in this age group

2. Indicate whether any children under 16 will be recruited as controls and give further details

3. Please describe the arrangements for seeking informed consent from a person with parental responsibility and/or from children able to give consent for themselves

4. If you intend to provide children under 16 with information about the research and seek their consent or agreement, please outline how this process will vary according to their age and level of understanding

From these overarching questions, key themes can be picked out that are familiar to children's geographers, namely: informed consent; potential benefits; and the potential harms of participation in research. However, by asking for reasons for carrying out the research with children under 16 specifically, arguably question 1 ignores a key concern of children's geographers who have fought to promote the agentic capacities of children in research and 
society more broadly (e.g. Bell and Members of the Glasgow Centre for the Child and Society, 2008), positioning children as competent social actors (see Alderson and Morrow, 2004; Hill, 2005). Further, we argue that the important ethical consideration of disparities of power is ignored in the NHS ethics process, which is an area explored by children's geographers (e.g. Christensen, 2004; Kellett et al., 2004; James, 2007). Perhaps this omission links to medical researcher's relative neglect of participatory approaches to research; that is researching with children (Scally, 2014). A further omission is the question of what relationships are built through the research, and how we take care of these (this has been a consideration of children's geographers such as King and Priestley, 2008 and Wilkinson, 2016).

Once completed, the IRAS form must be signed by the sponsor's representative, in our instance the sponsor was Edge Hill University, where the project is housed. After the form has been submitted online, the researcher is then required to phone up to book an appointment via a central booking line for the time and date the project will be reviewed by the REC. It takes up to 60 days for any application to be considered by an NHS REC. It is highly recommended that the researcher attends the meeting at which the research project is reviewed. From the first author's perspective of attending this meeting on $9^{\text {th }}$ August 2018 , it is comparable to a $\mathrm{PhD}$ Viva, as committee members (professionals and lay members) who have reviewed the application in advance, pose questions to the researcher (see Wisely, 2009 for a discussion of the makeup of ethics committee membership). The researcher is given the opportunity to clarify matters and defend certain choices made. An outcome of the application is usually received within a few weeks of the meeting. In our case, the outcome received on $23^{\text {rd }}$ August 2018 was: "the Committee is unable to give an ethical opinion on the basis of the information and documentation received so far". This was a frustrating outcome, bearing in mind that the study had already undergone a rigorous process of ethical approval and had been granted Faculty 
approval, in addition to the extensive IRAS application and supporting documents submitted via IRAS (including a research proposal; summary CV of chief investigator; participant information sheets; consent and assent forms; interview schedules; evidence of sponsor insurance; and summary of any applicable exclusions to sponsor insurance). The REC made the following requests:

1. Amend and rephrase questions in the diary templates to remove leading questions.

2. Confirm the age distribution of the potential participants.

a. And justification for including participants from the 4-11 year old group.

3. Ensure that the Informed Consent Form matches the Participant Information Sheet in regards to recording and transcribing interviews.

The age range for the study was initially proposed as 4-18 years. However, after the REC challenged the first author about the necessity of engaging 4-6 year olds in the study during the committee meeting, and after the panel raised the above query in the letter following the REC meeting, the research team decided that it would save time (in a time-sensitive study) in challenging this to compromise and raise the lower age range to 7 years old. Ultimately, 4-6 year olds were deprived an opportunity to talk to us about their experiences in this study due to an unwieldy ethical approval process and associated delays. This is something we remain disappointed about.

After addressing the points raised above and submitting the information, final NHS ethical approval was granted for the study on $24^{\text {th }}$ September 2018. Submission of the requested information was done electronically - it is not customary to be requested to attend a further meeting. Having successfully been approved by the ethics reviewing bodies, the next stage required obtaining R\&D approval to ensure that the NHS site has adequate arrangements and 
resources and finance to cover staff time. Approval for this was granted on $29^{\text {th }}$ October 2018. However, this was not the end of the road in terms of getting the study off the ground - we had to then gain confirmation of capacity from Alder Hey Children's Hospital, which required further form filling (including site-specific information) and email exchanges. This included each member of the research team gaining a 'Research Passport ${ }^{6}$ ' to undertake research at the site, a Disclosure and Barring Service check, and providing evidence of occupational health screening. We were given the 'go ahead' to finally commence the study on $14^{\text {th }}$ November 2018. In summary, from applying for ethics approval through IRAS, through the minefield of R\&D approvals and confirmation of capacity, this took more than six months. This is not taking into consideration the time to apply for, and gain, Faculty ethics approval prior to this.

For us, the length of time it took to gain final approvals was problematic. Our research was time-sensitive; children and young people were on a hair transplant surgery waiting list, and we were concerned that we would miss the opportunity to engage with these potential participants at the first timepoint of our study ( 2 weeks-4 months prior to transplant). Our concern here is not unique; Thompson and France (2010) also note that delays in their study were so severe that substantial parts of research could not be delivered as planned within their funding timescale.

\section{Conclusion}

In this Viewpoints piece, we have presented a case study to offer a description of the difficult journey that researchers who are attempting to recruit children via the NHS in England may face. There is a concern that the proliferation of ethical guidelines will limit the possibility of

\footnotetext{
6 The Research Passport provides evidence of the pre-engagement checks undertaken on the researcher in line with NHS Employment Check Standards.
} 
researching with children across different social, cultural and geographical contexts, in ways that are both ethical and locally appropriate (Abebe and Bessell, 2014). Whilst comprehensive in a broader sense, the IRAS form questions specific to children are arguably limited. As such, geographers should engage with their own understandings of ethics and children, and not solely be led by what is essentially an impersonal form. We noted omissions around power disparities and relationships with participants; both of these areas have been addressed well by children's geographers, but are not presented as important for studies undergoing NHS ethical approval.

Importantly, as Morrow and Richards (1996) note, it is impossible for researchers to foresee what ethical dilemmas will arise throughout the research process; as such, considering ethics as situational and responsive is essential. This may be particularly true of longitudinal studies, such as ours, where it is impossible to foresee all consequences of research participation on children's lives, as they unfold in unpredictable ways (Hampshire et al. 2012). In other words, no amount of box ticking and completing lengthy forms can mitigate the researcher's integrity, and how they think and behave whilst conducting research. The current system of NHS ethical approval has created a 'tick-a-box' mentality and could learn from social studies of childhood, and particularly geography, about the tensions between ethics, competence and participation (Skelton, 2008). Following Abebe and Bessell (2014), research with children should be respectful of children's rights and views, as well as robust and rigorous. Further, we argue for the importance of extending the degree of involvement of children in medical research, which whilst celebrated in the social sciences, is still considered uncertain territory in much medical research (Scally, 2014).

Of course, formal ethical approval processes, such as IRAS, have their merits in ensuring robust and rigorously scrutinised applications. However, practically speaking, such systems can cause researchers lengthy delays (Hallowell et al. 2008) and administrative burden. We argue that it 
is important for children's geographers to get to grips with applying for NHS ethical approval, particularly considering the move towards interdisciplinary working and engagement with children in underexplored spaces and places, such as: doctors surgeries; hospitals; dentists; and other services commissioned by the NHS. Our advice for fellow children's geographers who may be looking to undertake research via the NHS is to build sufficient time into project Gantt charts, funding applications, and the promise of project outputs to account for delays. 


\section{References}

Abede, Tatek. and Bessell, Sharon. (2014). Advancing ethical research with children: Critical reflections on ethical guidelines. Children's Geographies. 12. (1). pp. 126-133.

Alderson, Priscilla. and Morrow, Virginia. (2004). Ethics, Social Research and Consulting with Children and Young People. London: Barnardos.

Amin, Nadia. (2018). Completing an NHS ethics application: a fourth year students' perspective. Tomorrow's Pharmacist.

BBC (2017). The Drug Trial: Emergency at the hospital.

Bell, Nancy. (2008). Ethics in child research: Rights, reason and responsibilities. Children's Geographies. 6. (1). pp. 7-20.

Bell, Nancy and Members of the Glasgow Centre for the Child and Society (2008). Research ethics code of practice: Summary version (2005). Children's Geographies. 6. (1). pp. 95-108.

Christensen, Pia. H. (2004). Children's participation in ethnographic research: Issues of power and representation. Children \& Society. 18. (2). pp. 165-176.

King, Caroline and Priestley, Andrea. (2008). Ethics viewpoint. Children's Geographies. 6. (1). pp. 101-102. 
Ergler, Christine., Kearns, Robin., Witten, Karen. and Porter, Gina. (2016). Digital methodologies and practices in children's geographies. Children's Geographies. 14. (2). pp. 129-140.

Fudge, Nina., Redfern, Judith., Wolfe, Charles., and McKevitt., Christopher. (2010). Streamlined research governance: are we there yet?. British Medical Journal. 341. pp. 635637.

Hadjiconstantinou, Michelle and Forbat, Liz. (2012). Securing ethical permissions to conduct research with children. Securing ethical permissions to conduct research with children. Research Methods. 24. (1). pp. 22-25.

Hallowell, Nina., Cooke, Sarah., Crawford, Gill., Parker, Michael. and Lucassen, Anneke. (2008). Ethics and research governance: The views of researchers, health-care professionals and other stakeholders. Clinical Ethics. 3. pp. 85-90.

Halse, Christine. and Honey, Anne. (2005). Unravelling Ethics: Illuminating the Moral Dilemmas of Research Ethics. Signs: Journal of Women in Culture and Society. 30. (4). pp. $2141-2162$

Hampshire, Kate., Porter, Gina., Owusu, Samuel. et al. (2012). Taking the long view: Temporal considerations in the ethics of children's research activity and knowledge production. Children's Geographies. 10. (2). pp. 219-232.

Hill, Malcolm. (2005). Ethical considerations in researching children's experiences. In: S. Greene and D. Hogan (eds.) Researching Children's Experiences. London: Sage. pp. 61-86. 
James, Allison. (2007). Giving voice to children's voices: Practices and problems, pitfalls and potentials. American Anthropologist. 109. (2). pp. 261-272.

Jonker, Leon., Cox, Diane. and Marshall, Gill. (2011). Considerations, clues and challenges: Gaining ethical trust research approval when using the NHS as a research setting. Radiography. 17. pp. 260-264.

Kellett, Mary., Forrest, Ruth., Dent, Naomi., and Ward, Simon. (2004). 'Just teach us the skills please, we'll do the rest': empowering ten- year- olds as active researchers. Children \& Society. 18. (5). pp. 329-343.

Morrow, Virginia. and Richards, Martin. (1996). The Ethics of Social Research with Children: An Overview. Children and Society. 10. (2). pp. 90-105.

Rees, Colin. (2011). A simple guide to gaining ethical approval for perioperative nursing research. Research and Audit. 21. (4). pp. 123-127.

Rees, Michael. and Wells, Frank. (2010). Falling research in the NHS. British Medical Journal. pp. 1-2.

Robson, Elsbeth. (2018). Ethics committees, journal publication and research with children. Children's Geographies. 16. (5). pp. 473-480.

Scally, Andy. (2014). Ethical issues in research involving children and young people. Radiography. 20. pp. 202-205.

Skelton, Tracey. (2008). Research with children and young people: Exploring the tensions between ethics, competence and participation. Children's Geographies. 6. (1). pp. 21-36. 
Smajdor, Anna., Sydes, Matthew. R., Gelling, Leslie. and Wilkinson, Mark. (2009). Applying for ethical approval for research in the United Kingdom. British Medical Journal. 339. (7727). pp. $968-971$.

Thompson, Andrew. G.H. and France, E.F. (2010). One stop or full stop? The continuing challenges for researchers despite the new streamlined NHS research governance process. BMC Health Services Research.

Wilkinson, Catherine. (2016). "Babe, I like your lipstick”: Rethinking Researcher Personality and Appearance. Children's Geographies. 14. (1). pp. 115-123

Wisely, Janet. (2009). NRES: Challenges and opportunities. Research Ethics Review. 5. (1). pp. 14-17. 